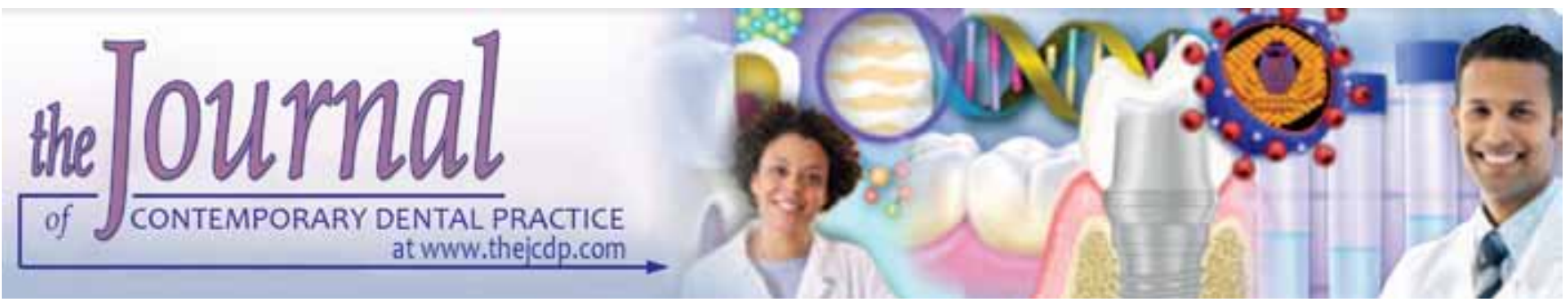

\title{
A Comparative Study between the Effect of Combined Local Anesthetic and Low-dose Ketamine with Local Anesthetic on Postoperative Complications after Impacted Third Molar Surgery
}

${ }^{1}$ Anuj Kumar, ${ }^{2}$ Tejraj Pundalik Kale

\begin{abstract}
Background: Postoperative pain, swelling and trismus are the most common outcome after third molar surgery. Many methods have been tried to improve postoperative comfort after surgery. Ketamine is a phencyclidine derivative that induces a state of dissociative anesthesia. It is a noncompetitive $\mathrm{N}$-methyl-D-aspartate (NMDA) receptor antagonist and has a distinct suppression effect on central nervous system (CNS) sensitization. Ketamine in a subanesthetic dose is set to produce analgesic and anti-inflammatory effect.
\end{abstract}

Materials and methods: Sixty patients, between the age group of 18 and 38 years, undergoing the extraction of impacted mandibular third molar, reporting to the department of oral and maxillofacial surgery were included in the study.

Patients were divided randomly into two groups: local anesthetic alone (LAA) and local anesthetic and ketamine (LAK).

Statistical analysis: Statistical analysis was performed using the Mann-Whitney U/unpaired-t-test and Wilcoxon signedrank test.

Result: There was a significant difference in mouth opening in the LAA and LAK group in the immediate postoperative period. There was a significant difference between the two groups after 1 hour (LAA: 2.37; LAK: 1.40), and 4 hours (LAA: 2.37; LAK: 1.40$)$.

There was a significant difference in terms of facial swelling in the immediate postoperative period and day 1 between the LAA and LAK group.

Clinical significance: Use of subanesthetic dose of ketamine is not only safe but also valuable in reducing patient morbidity after third molar surgery.

\footnotetext{
1,2Department of Oral and Maxillofacial Surgery, KLE Vishwanath
} Katti Institute of Dental Sciences, Belgaum, Karnataka, India

Corresponding Author: Anuj Kumar, Postgraduate, Department of Oral and Maxillofacial Surgery, KLE Vishwanath Katti Institute of Dental Sciences, Belgaum-590010, Karnataka, India, Phone: +919886982522, e-mail: dranuj21@gmail.com
Conclusion: Combination of a local anesthetic and subanesthetic dose of ketamine during surgical extraction of third molars provides good postoperative analgesia with less swelling and significantly less trismus.

Keywords: Ketamine, Postoperative complication, Third molar.

How to cite this article: Kumar A, Kale TP. A Comparative Study between the Effect of Combined Local Anesthetic and Low-dose Ketamine with Local Anesthetic on Postoperative Complications after Impacted Third Molar Surgery. J Contemp Dent Pract 2015;16(12):957-962.

Source of support: Nil

Conflict of interest: None

\section{INTRODUCTION}

Surgical management of impacted third molars is a common treatment routinely dispensed in the oral and maxillofacial surgery. ${ }^{1}$

Extensive training, experience and skill are necessary to perform the procedure with minimal trauma. The incident of complications rises significantly if the surgeon is inexperienced. ${ }^{2}$

Though the overall incident of complication is low and most complications are minor in nature, third molar removal is so common that the morbidity of complications becomes significant. ${ }^{3}$

Hence, any effort to limit the intraoperative and postoperative complications has a great impact on enhancement of patient outcome. ${ }^{3}$

Common postsurgical outcome after third molar surgery are pain, limitation of mouth opening and swelling. ${ }^{2}$ Postsurgical pain begins when the effect of the local anesthesia subsides and reaches its maximum intensity during the first 12 hours postoperatively. ${ }^{2}$ 
Trismus is expected and normal outcome following third molar surgery and reaches its peak on the 2nd day and resolves by the end of the 1st week. ${ }^{2}$

Postsurgical edema or swelling is expected sequelae of third molar surgery. The swelling reaches its peak by 2nd postoperative day and subsides by the 7 th day. ${ }^{2}$

Many therapeutic protocols have been designed to improve the postoperative comfort of the patient including different kind of flaps, ${ }^{4}$ draining of wounds, ${ }^{5}$ piezoelectric surgery, ${ }^{6}$ postoperative extraoral and intraoral low level laser therapy, ${ }^{7}$ the postoperative application of ice pack, ${ }^{8}$ and postoperative systemic or topical application of various analgesics, muscle-relaxants, corticosteroids, anti-inflammatory drugs and antibiotics to suppress the mediators of inflammation which will reduce fluid transudation and will lessen edema. ${ }^{9-11}$

Ketamine is a phencyclidine derivative that induces a state of dissociative anesthesia. ${ }^{1}$ This is characterized as 'dissociation' between the thalamocortical and limbic systems, producing a cataleptic state during which the patient may appear awake but does not respond to commands. ${ }^{1}$

It is a noncompetitive N-methyl-D-aspartate (NMDA) receptor antagonist and has a distinct suppression effect on central nervous system (CNS) sensitization. ${ }^{12}$ It acts synergistically with opioids, inhibiting tolerance and rebound hyperalgesia. ${ }^{12}$

The primary site of action is in the cortex and subcortical area. It elevates heart rate, cardiac output and blood pressure due to sympathetic stimulation. ${ }^{13}$

A dose of 1 to $3 \mathrm{mg} / \mathrm{kg}$ i.v. or 6.5 to $13 \mathrm{mg} / \mathrm{kg}$ i.m. produces that effect within minute and recovery starts after 10 to 15 minutes. ${ }^{13}$

Ketamine in a subanesthetic dose of $0.3 \mathrm{mg} / \mathrm{kg}$ produces analgesic effect. ${ }^{14}$ The inhibition of NMDA receptors decreases neuronal signaling and is likely responsible for some of ketamine's analgesic effects.

Thus, in a higher dose it acts as an intravenous anesthetic, whereas low dose ketamine acts as an analgesic. ${ }^{14}$

As per several studies, apart from anesthetic activity, ketamine also has anti-inflammatory effects. ${ }^{15,16}$

This study aims at the assessment of the clinical efficacy of combined treatment of ketamine in a subanesthetic dose and local anesthetic for the relief of postoperative pain, swelling and trismus after the surgical extraction of lower third molar as compared to local anesthetic alone.

\section{DESIGN AND METHODS}

Sixty patients between the age group of 18 and 38 years, undergoing the extraction of impacted mandibular third molar, reporting to the Department of Oral and Maxillofacial Surgery at KLE Vishwanath Katti Institute of Dental Sciences, Belgaum, India were included in the study.
Clearance was obtained from the KLE University Ethical Clearance Committee.

\section{Inclusion Criteria}

- Patients who will undergo extraction of impacted mandibular third molar teeth between the age-group of 18 and 38 years.

- Patients should have a moderately difficult impaction as per Pederson's difficulty index.

\section{Exclusion Criteria}

- Patients with a history of systemic diseases like hypertension and congestive heart failure which contraindicates the administration of the experimental drug.

- Patients who are currently on anti-psychotic drug or have a history of anti-psychotic treatment

- Patients with a history of drug-addiction

- Patients with a history of allergy to the experimental drug

- Patients who are currently under medication with opioid drugs

- Pregnant women or women in the breastfeeding period

The patients were divided randomly into two groups:

- Local anesthetic alone (LAA)

- Local Anesthetic and ketamine (LAK).

All local anesthetic blocks and surgical procedure were performed by the surgeons with same surgical experience in performing third molar surgery.

The patient in LAA group received $5 \mathrm{ml}$ of solution comprising of $2 \mathrm{ml}$ of local anesthetic ( $2 \%$ lignocaine with 1:80000 adrenaline) and $3 \mathrm{ml}$ of normal saline.

The patients in LAK group received $5 \mathrm{ml}$ of solution comprising of $2 \mathrm{ml}$ of local anesthetic ( $2 \%$ lignocaine with $1: 80000$ adrenaline) and $0.3 \mathrm{mg} / \mathrm{kg}$ body weight ketamine and saline.

\section{SURGICAL TECHNIQUE}

Each patient underwent similar surgical procedure, in the same operating room and under similar conditions.

Inferior alveolar, lingual and buccal nerve block were carried out. Standard Ward's incision was given; following which mucoperiosteal flap was raised.

After exposing the bone around the tooth, guttering was done using the bur, with copious saline irrigation. Tooth sectioning was done if required.

After tooth removal, the alveolus was inspected for any sharp margins and was curetted for removal of granulation tissue. Irrigation was done with betadine and sterile saline solution.

A 2/0 silk suture was used to close the wound without tension. 
After the surgery, patients were provided with a 10-point visual analog scale (VAS: 0 , no pain; 10 , agonizing pain) at 30 minutes and 1, 4, 12, 24 hours after surgery.

The level of facial swelling was determined by the distance in millimeter between following landmarks:

- Palpebral external angle and the gonial angle of the operated side, known as angle of eye-angle of the jaw (AE-AJ)

- Lower margin of the tragus to the external angle of the buccal commissure, known as tragus-angle of mouth (T-AM)

- Lower margin of the tragus to the middle point of the symphysis menti, known as tragus-pogonion (T-P).

The sum of these three measurements was considered as a baseline for that side of the face. The difference between postoperative measurement and preoperative measurement indicated the extent of facial swelling. An assessment was done on immediate postoperative period, postoperative day 1,3 and 7 .

Trismus was evaluated by measuring mouth opening preoperatively, immediate postoperative period and 1,3 and 7 days postoperatively by measuring distance between the mesio-incisal corners of the upper and lower right central incisors at maximum opening of the jaws.

After surgery all the patients were given Aceclofenac plus paracetamol for 3 days.

Statistical analysis was performed using the MannWhitney U/unpaired t-test and Wilcoxon signed-rank test.

\section{RESULT}

Sixty patients were included in the study. Out of 60 patients, 25 male patients and 35 female patients were included.

In the LAA group, 19 female and 11 male patients were present, whereas in the LAK group, 16 female and 14 male patients were included.

Mean age of patients included in the LAA group was 26.67 years and in the LAK group was 26.17 years.

There was a significant difference in mouth opening in the LAA and LAK group in the immediate postoperative period (LAA: 3.06; LAK: 3.52), on day 1 (LAA: 2.80; LAK: 3.30), on day 3 (LAA: $3.40 ;$ LAK: 3.65 ) and on day 7 (LAA: 4.14; LAK: 4.40) (Table 1).

Pain assessment was done on a VAS. The mean score after 30 minutes in LAA group was 2.13, whereas in LAK group it was 1.77 , which was statistically not significant (Table 2).

However, there was a significant difference between the two groups after 1 hour (LAA: 2.37; LAK: 1.40), and 4 hours (LAA: 2.37; LAK: 1.40 ).

After 12 hours (LAA: 2.40; LAK: 2.17) and 24 hours (LAA: 1.90; LAK: 2.07) the difference between the two groups was not statistically significant.

There was a significant difference in terms of facial swelling in the immediate postoperative period and day 1 between the LAA and LAK group (Table 3).

However, the difference was not significant on day 3 and 7.

Table 1: Comparison of control and ketamine groups with respect to mouth opening at different time points by Mann-Whitney $U$ test

\begin{tabular}{|c|c|c|c|c|c|c|c|c|}
\hline Time points & Groups & Mean & $S D$ & Median & Sum of ranks & u-value & z-value & $p$-value \\
\hline \multirow[t]{2}{*}{ Preoperative } & Control & 4.55 & 0.27 & 4.50 & 782.00 & 317.00 & -1.9663 & $0.0493^{*}$ \\
\hline & Ketamine & 4.69 & 0.25 & 4.75 & 1048.00 & & & \\
\hline \multirow[t]{2}{*}{ Postoperative } & Control & 3.06 & 0.42 & 3.15 & 679.50 & 214.50 & -3.4817 & $0.0005^{*}$ \\
\hline & Ketamine & 3.52 & 0.70 & 3.60 & 1150.50 & & & \\
\hline \multirow[t]{2}{*}{ Day 1} & Control & 2.80 & 0.48 & 2.80 & 651.00 & 186.00 & -3.9031 & $0.0001^{*}$ \\
\hline & Ketamine & 3.30 & 0.55 & 3.35 & 1179.00 & & & \\
\hline \multirow[t]{2}{*}{ Day 3} & Control & 3.40 & 0.46 & 3.50 & 736.00 & 271.00 & -2.6464 & $0.0081^{*}$ \\
\hline & Ketamine & 3.65 & 0.48 & 3.65 & 1094.00 & & & \\
\hline \multirow[t]{2}{*}{ Day 7} & Control & 4.14 & 0.38 & 4.10 & 722.00 & 257.00 & -2.8534 & $0.0043^{*}$ \\
\hline & Ketamine & 4.40 & 0.40 & 4.50 & 1108.00 & & & \\
\hline \multirow{2}{*}{$\begin{array}{l}\text { Preoperative to } \\
\text { postoperative }\end{array}$} & Control & 1.49 & 0.42 & 1.40 & 1107.00 & 258.00 & -2.8386 & $0.0045^{\star}$ \\
\hline & Ketamine & 1.18 & 0.67 & 1.00 & 723.00 & & & \\
\hline \multirow{2}{*}{$\begin{array}{l}\text { Preoperative to } \\
\text { day } 1\end{array}$} & Control & 1.76 & 0.56 & 1.80 & 1093.50 & 271.50 & -2.6390 & $0.0083^{*}$ \\
\hline & Ketamine & 1.39 & 0.61 & 1.30 & 736.50 & & & \\
\hline \multirow{2}{*}{$\begin{array}{l}\text { Preoperative to } \\
\text { day } 3\end{array}$} & Control & 1.15 & 0.54 & 1.00 & 988.00 & 377.00 & -1.0793 & 0.2805 \\
\hline & Ketamine & 1.05 & 0.54 & 0.90 & 842.00 & & & \\
\hline \multirow{2}{*}{$\begin{array}{l}\text { Preoperative to } \\
\text { day } 7\end{array}$} & Control & 0.41 & 0.36 & 0.30 & 1028.00 & 337.00 & -1.6706 & 0.0948 \\
\hline & Ketamine & 0.30 & 0.37 & 0.20 & 802.00 & & & \\
\hline
\end{tabular}

${ }^{*} p<0.05$ 
Table 2: Comparison of control and ketamine groups with respect to pain scores at different time points by Mann-Whitney $U$ test

\begin{tabular}{|c|c|c|c|c|c|c|c|c|}
\hline Time points & Groups & Mean & $S D$ & Median & Sum of ranks & u-value & z-value & $p$-value \\
\hline \multirow[t]{2}{*}{30 minutes } & Control & 2.13 & 1.14 & 2.00 & 976.00 & 389.00 & -0.9018 & 0.3671 \\
\hline & Ketamine & 1.77 & 0.86 & 2.00 & 854.00 & & & \\
\hline \multirow[t]{2}{*}{1 hour } & Control & 2.37 & 1.16 & 2.00 & 1135.50 & 229.50 & -3.2600 & $0.0011^{*}$ \\
\hline & Ketamine & 1.40 & 0.86 & 1.00 & 694.50 & & & \\
\hline \multirow[t]{2}{*}{4 hours } & Control & 2.83 & 1.12 & 3.00 & 1076.50 & 288.50 & -2.3877 & $0.0170^{*}$ \\
\hline & Ketamine & 2.10 & 0.88 & 2.00 & 753.50 & & & \\
\hline \multirow[t]{2}{*}{12 hours } & Control & 2.40 & 1.13 & 2.00 & 965.00 & 400.00 & -0.7392 & 0.4598 \\
\hline & Ketamine & 2.17 & 1.26 & 2.00 & 865.00 & & & \\
\hline \multirow[t]{2}{*}{24 hours } & Control & 1.90 & 1.42 & 2.00 & 828.00 & 363.00 & -1.2862 & 0.1984 \\
\hline & Ketamine & 2.07 & 0.94 & 2.00 & 1002.00 & & & \\
\hline \multirow[t]{2}{*}{30 minutes to 1 hour } & Control & -0.23 & 1.57 & -0.50 & 772.50 & 307.50 & -2.1068 & $0.0351^{*}$ \\
\hline & Ketamine & 0.37 & 0.93 & 0.50 & 1057.50 & & & \\
\hline \multirow[t]{2}{*}{30 minutes to 4 hours } & Control & -0.70 & 1.76 & -0.50 & 861.50 & 396.50 & -0.7910 & 0.4290 \\
\hline & Ketamine & -0.33 & 1.09 & -1.00 & 968.50 & & & \\
\hline \multirow[t]{2}{*}{30 minutes to 12 hours } & Control & -0.27 & 1.66 & -1.00 & 925.00 & 440.00 & -0.1478 & 0.8825 \\
\hline & Ketamine & -0.40 & 1.33 & 0.00 & 905.00 & & & \\
\hline \multirow[t]{2}{*}{30 minutes to 24 hours } & Control & 0.23 & 1.48 & 0.00 & 1028.50 & 336.50 & -1.6780 & 0.0934 \\
\hline & Ketamine & -0.30 & 1.34 & 0.00 & 801.50 & & & \\
\hline
\end{tabular}

${ }^{*} p<0.05$

Table 3: Comparison of control and ketamine groups with respect to swelling at different time points by Mann-Whitney $U$ test

\begin{tabular}{|c|c|c|c|c|c|c|c|c|}
\hline Time points & Groups & Mean & $S D$ & Median & Sum of ranks & u-value & z-value & $p$-value \\
\hline \multirow[t]{2}{*}{ Preoperative } & Control & 32.25 & 1.52 & 32.00 & 873.50 & 408.50 & -0.6136 & 0.5395 \\
\hline & Ketamine & 32.47 & 1.38 & 32.50 & 956.50 & & & \\
\hline \multirow[t]{2}{*}{ Immediate postoperative } & Control & 32.60 & 1.57 & 32.50 & 908.50 & 443.50 & -0.0961 & 0.9234 \\
\hline & Ketamine & 32.63 & 1.38 & 33.00 & 921.50 & & & \\
\hline \multirow[t]{2}{*}{ Day 1} & Control & 34.05 & 1.60 & 34.00 & 946.00 & 419.00 & -0.4583 & 0.6467 \\
\hline & Ketamine & 33.90 & 1.49 & 34.00 & 884.00 & & & \\
\hline \multirow[t]{2}{*}{ Day 3} & Control & 34.75 & 1.42 & 35.00 & 909.00 & 444.00 & -0.0887 & 0.9293 \\
\hline & Ketamine & 34.70 & 1.37 & 35.00 & 921.00 & & & \\
\hline \multirow[t]{2}{*}{ Day 7} & Control & 32.75 & 1.52 & 32.50 & 879.50 & 414.50 & -0.5248 & 0.5997 \\
\hline & Ketamine & 32.92 & 1.40 & 33.00 & 950.50 & & & \\
\hline \multirow{2}{*}{$\begin{array}{l}\text { Preoperative to } \\
\text { immediate postoperative }\end{array}$} & Control & 0.35 & 0.30 & 0.50 & 1060.00 & 305.00 & -2.1437 & $0.0321^{*}$ \\
\hline & Ketamine & 0.17 & 0.24 & 0.00 & 770.00 & & & \\
\hline \multirow[t]{2}{*}{ Preoperative to day 1} & Control & 1.80 & 0.71 & 1.75 & 1070.50 & 294.50 & -2.2990 & $0.0215^{*}$ \\
\hline & Ketamine & 1.43 & 0.43 & 1.50 & 759.50 & & & \\
\hline \multirow[t]{2}{*}{ Preoperative to day 3} & Control & 2.50 & 0.80 & 2.50 & 995.50 & 369.50 & -1.1901 & 0.2340 \\
\hline & Ketamine & 2.23 & 0.58 & 2.50 & 834.50 & & & \\
\hline \multirow[t]{2}{*}{ Preoperative to day 7} & Control & 0.50 & 0.53 & 0.50 & 943.50 & 421.50 & -0.4214 & 0.6735 \\
\hline & Ketamine & 0.45 & 0.30 & 0.50 & 886.50 & & & \\
\hline
\end{tabular}

${ }^{*} p<0.05$

\section{DISCUSSION}

Surgical removal of the impacted lower third molar is frequently associated with swelling, pain and limitation of mouth opening which are generally due to inflammatory response.

To enhance the overall satisfaction of the patient it is important to reduce the intra and postoperative discomfort which are associated with the procedure.

Ketamine is a NMDA receptor antagonist and has an analgesic and anti-inflammatory effect on subanesthetic dose.
In this study, we have assessed swelling and mouth opening immediate postoperatively on day 1, 3 and 7 .

Assessment of pain on VAS was done postoperatively after 30 minutes, 1, 4, 12 and 24 hours.

In the earlier studies which were done, there was no assessment of swelling and mouth opening in the immediate postoperative period.

\section{SWELLING}

To decrease the inflammatory response after surgery, surgeons often use corticosteroids. Zandi compared 
the effect of surgical drains and corticosteroids. They concluded that corticosteroids are more effective in reducing postoperative edema and pain. However, no significant difference was seen in reducing trismus. ${ }^{17}$

Ustun et al studied the effect of intravenous administration of methylprednisolone sodium succinate at 1.5 and $3 \mathrm{mg} / \mathrm{kg}$. He concluded that there is no statistical significant difference in pain, trismus, or facial swelling between the two doses. ${ }^{18}$

Laureano Filho et al compared the effect of two doses of dexamethasone and concluded that $8 \mathrm{mg}$ dexamethasone is more effective in reducing the amount of trismus and swelling. However, it does not have a significant effect on the pain control. ${ }^{19}$

Although corticosteroids are highly effective in preventing the trismus and swelling, it was not used in the present study, as we evaluated an anti-inflammatory effect of ketamine.

Our result showed that the amount of trismus was significantly less on all postoperative day in LAK group. Hence, ketamine may be useful in those patients who are contraindicated for administration of corticosteroids.

In a study conducted by Tulin Satilmis et al where 50 patients were included to assess the efficacy of combined local anesthetic and subanesthetic ketamine for the relief of postoperative swelling, pain and trismus after surgical removal of third molar, facial swelling on the postoperative day 1, 3 and 7 was lower in LAK group than in the LAA group $(p=0.0001) .{ }^{12}$ Though the facial swelling was significantly increased in both the groups on postoperative day 3 , facial swelling was still less significant in the LAK group as compared to LAA group.

The authors observed a significant decrease in swelling between postoperative day 3 and $7(p=0.001)$.

No significant difference in relation to facial swelling was seen in the LAA group between postoperative day 1 and 7. However, the LAK group showed a significant decrease in facial swelling between postoperative day 1 and 7.

Garip et al in their study to assess efficacy of midazolam plus low dose ketamine conscious intravenous sedation concluded that facial swelling on postoperative day 1 , 3 and 7 was significantly less in the ketamine group as compared to the control group. ${ }^{12}$

Gupta et al included 30 patients with bilateral impacted lower third molar. On the right side, a combination of low dose ketamine $(5 \mathrm{mg} / \mathrm{kg}$ ) and oral midazolam $(0.25 \mathrm{mg} / \mathrm{kg})$ was given. ${ }^{20}$ Left side was kept as control.

Measurement of swelling revealed that only five patients showed a slight swelling on the right side. Twelve patients showed swelling on the left side.

In our study also, there was a decrease in facial swelling in the ketamine group. The result showed significant difference in terms of facial swelling in the immediate postoperative period and day 1 between the control and the ketamine group. However the difference was not significant on day 3 and 7 .

\section{MOUTH OPENING}

Garip et al observed that the mouth opening in the LAA group differed significantly among postoperative day 1 , 3 and $7 .{ }^{12}$ However, in the LAK group mouth opening on postoperative day 1 was not significantly different than that on postoperative day 3. Mouth opening was, however, significantly different between postoperative day 1 and 7.

Garip et al also concluded that the degree of trismus on postoperative day 1 and three was significantly lesser in ketamine group. ${ }^{12}$

Our study showed similar results with significant improvement in mouth opening on postoperative day 1,3 and 7.

\section{PAIN}

In the study done by Garip et al, the VAS score at 30 minutes and 1, 4, 12 and 24 hours after surgery was higher significantly in the control group as compared to ketamine group. ${ }^{12}$

Gupta et al in their study concluded that pain level was lowered significantly when ketamine was given after third molar surgery. ${ }^{20}$

Kaviani et al in their clinical trial over 36 patients with irreversibly inflamed mandibular molar studied the effect of oral ketamine on the dosage of local anesthetic required and postoperative pain management, also observed that the mean score on VAS for intraoperative pain in the ketamine group was less than that in the control group. ${ }^{21}$

Garip et al showed similar result and the VAS score at 4, 12 and 24 hours after surgery was higher significantly in the control group as compared to ketamine group. ${ }^{12}$

In a comparative study to evaluate the effect of low dose intravenous and subcutaneous ketamine in posttonsillectomy pain relief, Javid et al concluded that pain score was much higher in the control group compared to the other two groups of intravenous and subcutaneous ketamine. $^{22}$

Dal et al in their study to investigate the effect of peritonsillar infiltration of low dose ketamine on reducing the postoperative pain in children undergoing adenotonsillectomy concluded that it provides adequate pain relief without any side effect. ${ }^{7}$

Erhan et al also reported that infiltration of ketamine is an effective and easy way of providing analgesia after tonsillectomy. ${ }^{9}$

Lebrun et al, however, concluded that the low dose IV ketamine $(0.3 \mathrm{mg} / \mathrm{kg})$ provides no benefit in relieving the postoperative pain in outpatients after oral surgery. ${ }^{23}$ 
However, in our study mean value of pain on VAS was significantly lower in the LAK group after 1 and 4 hours.

\section{ADVERSE EFFECT}

Few problems were encountered during the study done by Garip et al. ${ }^{12}$ Two patients in the control group and none in the ketamine group experienced nausea and weakness. Two patients in the ketamine group reported having dreams during surgery but could not recall the dream.

In our study, we encountered one patient in LAK group who complained of talkativeness, euphoria and dizziness after ketamine was administered. Monitoring of vital signs showed tachycardia with an increased pulse rate. Regular monitoring of vital signs was done for 15 minutes after which patient recovered.

\section{ACKNOWLEDGMENT}

The authors thank all the patients that voluntarily participated in this research and KLE Vishwanath Katti Institute of Dental Sciences, Belgaum, Karnataka for the material support required for the surgical procedure.

\section{REFERENCES}

1. Aras MH, Gungormus M. The effect of low level laser therapies on trismus and facial swelling following surgical extraction of a lower third molar. Photomed Laser Surg 2009; 27:21-25.

2. Buyukkurt MC, Gungormus M, Kaya O. The effect of a single dose prednisolone with and without diclofenac on pain, trismus, and swelling after removal of mandibular third molar. J Oral Maxillofac Surg 2006;64:1761-1765.

3. Bui $\mathrm{CH}$, Seldin EB, Dodson TB. Types, frequencies, and risk factors for complications after third molar extraction. J Oral Maxillofac Surg 2003;61:1379-1389.

4. Cho JE, Shim JK, Choi YS, Kim DH, Hong SW, Kwak YL. Effect of low dose ketamine on inflammatory response in off-pump coronary artery bypass graft surgery. Br J Anaesth 2009;102:23-27.

5. Chopra D, Rehan HS, Mehra P, Kakkar AK. A randomized, double blind, placebo-controlled study comparing the efficacy and safety of paracetamol, serratiopeptidase, ibuprofen and betamethasone using the dental impaction pain model. Int J Oral Maxillofac Surg 2009;38:350-354.

6. Jaggar S, Holdcroft A. Core topics in pain. 1st ed: Cambridge University Press 2005. p. 121.

7. Dal D, Celebi N, Elvan EG, Celiker V, Aypar U. The efficacy of intravenous or peritonsillar infiltration of ketamine for postoperative pain relief in children following adenotonsillectomy. Paediatr Anaesth 2007 Mar;17(3):263-269.

8. Landari E, Hustveit O, Trumpy IG, Skjelbred P. Ketamine as single dose analgesic on acute postoperative pain in both genders following surgical removals of third molars. J Oral Maxillofac Surg 2013;71(9):e38-42.

9. Erhan OL, Göksu H, Alpay C, Beştaş A. Ketamine in posttonsillectomy pain. Int J Pediatr Otorhinolaryngol 2007 May; 71(5):735-739.
10. Tripathi KD. Essentials of medical pharmacology. 5th Edition. Jaypee Brothers Medical Publishers (P) Ltd., New Delhi, India 2004. p. 48

11. Yildirim G, Guroytrk B, Apiliogullari S, Cakir M, Najafov E, Dolanmaz D. Effects of low dose ketamine combined with local anesthetic on postoperative complications after impacted third molar surgery. Int J Oral Maxillofac Surg 2011;40(10):1054-1055.

12. Garip H, Satilmis T, Dergin G, Uğurlu F, Göker K. Effect of midazolam/low dose ketamine conscious intravenous sedation on pain, swelling, and trismus after surgical extraction of third molar. J Oral Maxillofac Surg 2011;69: 1023-1028.

13. Ata-Ali J, Ata-Ali F, Peñarrocha-Oltra D, Peñarrocha $M$. Corticosteroids use in controlling pain, swelling and trismus after lower third molar surgery. J Clin Exp Dent 2011;3(5):e469-475.

14. de Sousa Santos JAS, da Silva LCF, de Santana Menezes Júnior TLR, de Assunção Oliveira AC, Brandão JR. Comparative study of tramadol combined with dexamethasone and diclofenac sodium in third-molar surgery. J Craniomaxillofacial Surgery xxx (2012) $1 \mathrm{e} 7$.

15. Kirk DG, Liston PN, Tong DC, Love RM. Influence of two different flap design on incidence of pain, swelling trismus and alveolar osteitis in the week following third molar surgery. Oral Surg Oral Med Oral Pathol Oral Radiol Endod 2007;4:1-7.

16. Kirmeirer R, Truschnegg A, Payer M, Payer M, Acham S, Schulz K, Jakse N. Evaluation of a muscle relaxant on sequelae of third molar surgery: a pilot study. Oral Surg Oral Med Oral Pathol Oral Radiol Endod 2007;104:8-15.

17. Zandi M. Comparison of corticosteroids and rubber drain for reduction of sequelae after third molar surgery. Oral Maxillofac Surg 2008;12:29-35.

18. Ustun Y, Erdogan O, Esen E, Karsli ED. Comparison of the effect of two doses of methylprednisolone on pain, swelling, and trismus after third molar surgery. Oral Surg Oral Med Oral Pathol Oral Radiol Endod 2003;96:535-540.

19. Laureano Filho JR, Maurette PE, Allais M, Cotinho M, Fernandes C. Clinical comparative study of the effectiveness of two dosage of dexamethasone to control postoperative swelling, trismus and pain after the surgical extraction of mandibular impacted thid molars. Med Oral Pathol Oral Cir Buccal 2008;13:129-135.

20. Gupta R, Sharma K, Dhiman UD. Effect of combination of oral midazolam and low dose ketamine on anxiety, pain, swelling and comfort during and after surgical extraction of mandibular third molars. Ind J Dent Res 2012 MarApr;23(2):295-296.

21. Kaviani N, Khademi A, Ebatehaj I, Mohammadi Z. The effect of orally administered ketamine on requirement for anesthetic and postoperative pain in mandibular molar teeth with irreversible pulpitis. J Oral Sci 2011;53(\$):461-465.

22. Javid MJ, Hajijafari M, Hajipour A, Makarem J. Evaluation of a low dose ketamine in post tonsillectomy pain relief: a randomized trial comparing intravenous and subcutaneous ketamine in pediatrics. Anesth Pain Med 2012 Autumn;2(2): 85-89.

23. Lebrun T, Van Elstraete AC, Sandefo I, Polin B, Pierre-Louis L. Lack of a pre-emptive effect of low dose ketamine on postoperative pain following oral surgery. Can J Anesth 2006; 53:146-152. 